\title{
FROM PASSENGER TO DRIVER: CREATIVITY AND CULTURE IN RURAL COMMUNITIES
}

\author{
PATRICK MITCHELL* and RON FISHER $\dagger$ \\ *School of Education and Professional Studies, Gold Coast Campus, Griffith University, Australia \\ $\dagger$ Centre for Tourism, Sport and Service Innovation, Gold Coast Campus, Griffith University, Australia
}

\begin{abstract}
This study examines the activities of an arts group in a small rural town in Australia through the lens of the Creative Industries paradigm. The aim of the study is to gain deeper understanding of the potential of arts activities to impact on a community. The study evaluates how future growth of the arts in such communities may be augmented by use of the paradigm supported by a branding approach based on creativity and innovation. The research uses in-depth interviews of volunteers and other key actors in a rural arts festival. Findings suggest that the Creative Industries paradigm provides a framework that supports and develops the work of community art in rural communities. The paradigm also supports the development of a branding strategy based on creativity and innovation.
\end{abstract}

Key words: The arts; Creative industries; Tourism

\section{Introduction}

This research is about the capacity of the arts to make a significant contribution to the quality of life in a rural community in Australia. A Queensland Arts Council (QAC) program, on which this study is based, involved the principal researcher in work with 18 rural communities over a 3-year period. The purpose of the QAC project was to move the arts from a niche or ancillary activity in a community to a position where it had the capacity to sustain communities in times of rapid social and economic change. The aim of the research was to change the arts, and its practitioners, from "pas- sengers" in the journey of community life, to being "drivers."

A concern arising from the QAC project was how ways could be found for current arts policies and practice to impact to a greater degree on rural communities. Rural communities are often seen as "difficult" and in need of various forms of assistance by funding bodies. As a consequence arts policy in Australia has been based on what these communities lack, providing them with an almost mendicant status in their relationship with government policy and delivery. Under the rubric of the QAC project this study sought to explore the situation in the context of a specific arts activity in 
order to find new ways to understand the social and cultural impact of the arts on rural communities. Doing this was expected to inform and lead government and community attitudes and policies to the arts.

The research is a qualitative case study that evaluates an arts activity in a contemporary Australian rural community in Queensland. The conceptual basis for the research is the Creative Industries paradigm, proposed by Cunningham (2006) as a framework for harnessing the creativity of people and communities. Use of the paradigm also supports a branding approach based on creativity and innovation.

\section{Literature Review}

\section{The Usefulness of the Arts}

Mitchell (2007) asks what do we mean by the arts? Is it that personal, private experience or benefit we have as individuals when witnessing a concert, painting, play, or a film? Do we mean that more public experience when we gather as a group in a gallery, theater, or a concert venue? Do we mean a body of work or group of individuals or organizations that are provided with government funding to produce that work? Or do we focus on that capacity of the arts to be useful; to be instrumental in achieving some outcome that is deemed beneficial to our community or ourselves? This study examines the latter two perspectives, considering some of the recent discussion on the capacity of arts activities to benefit people and circumstances. In doing this the research focuses on the present parlous state of the arts and its difficult, perhaps mendicant, relationship with the broader community and government (Mitchell, 2007).

There is much literature about the arts doing more than providing aesthetic pleasure and diversionary entertainment (e.g., Yencken, 2001). Cultural policies, of which the arts are often an instrument, do have the capacity to enrich lives in many different ways. Richards (2006) believes that the arts "stimulate, revitalize and refresh" (p. 32) in activities that encompass the whole community. Mills and Brown (2004) extend the notion of the enrichment of life through the arts by highlighting seven distinct areas of impact or benefit: a) active citizenship; b) social inclusion and cultural diver- sity; c) rural revitalization; d) public housing and place; e) community strengthening; f) health; and g) ecologically sustainable development. Matarasso (2004) has proposed 50 different ways that the arts could have positive social impact. Matarasso (2004), like Mills and Brown (2004), has categorized the impact of the arts into different areas: a) personal development; b) social cohesion; c) community empowerment and self-determination; d) local image and identity; e) imagination and vision; and f) health and well-being.

An alternative view of the value of the arts has been presented by Carey (2005), who points out that empirically there are few examples of the betterment of people from exposure to the arts. However, Carey (2005) does find that active participation in the arts "alters people" (p. 158), although the art world has paid little attention to this phenomenon. While the art world may have neglected the reformative powers of art, government, and community groups have been assiduous in utilizing the arts as a "civilizing force" with which to shape people (Gibson, 2001). In Australia the parallels exist across time with the establishment of the Sydney Mechanics School of Arts in 1833, with its mission of maintaining civilized ways in a new country, and the Queensland government's recent commitment to a State library redevelopment in 2001 (Gibson, 2001). This commitment was also evident with the construction of the Modern Art Gallery in Brisbane in 2006, being a civilizing force and therefore beneficial to the community (Mitchell, 2007).

Politically, the arts were used to construct national identity in the 1920 s, a framer of national character and purpose in the 1950s post-war period, and as a promoter of national identity in the latter part of the 20th century (Gibson, 2001). Gibson (2001) argues that the programmatic and institutional uses of art are constructed on the basis of forms of identity. However, she sounds a warning that we need to be particular about what our uses for art are, who is using them, and to what end.

\section{Arts in the Community}

Hawkes (2001) has suggested that the future of a society is at risk when arts practice is not embedded in everyday life. In Hawkes' view a commu- 
nity can only develop a vibrant and effective culture when it has cultivated its "own creative capabilities." He argues that a community that grows its arts base will find that "creativity, engagement, cohesiveness and respect for difference will be inevitable outcomes" (p. 24). Art also performs a role in catalyzing and linking public interest around key civic issues (e.g., a water project) in small communities, with the consequence of adding clarity and positive direction in public dialogue and debate (Yuen, 2003). The significance of arts in rural communities has been suggested by Matarasso (2004) in his assessment of the impact of rural arts touring. In this he argues that the arts significantly contribute to the social, cultural, and economic life of a community and therefore should be an important element in any social or economic strategy (Matarasso, 2004). However, recent policy frameworks have tended to link the arts with market realities, thus eroding the social capital of communities and having a negative effect on cohesion, cooperation, and inclusion (Kingma, 2004). The negative effects of policy emphasize the importance of cultural activities, particularly the arts, in "reconnecting with the spiritual, generating social capital, breaking down relationship barriers and transmitting information" (p. 63).

In Australia there have been many changes in Federal and State government arts policy, funding levels and activities over the past three decades. Latham (2004) reports that in the early 1970s, $80 \%$ of arts funding went to individual artists with $20 \%$ going to organizations. Thirty years later, the percentages have been reversed, with $80 \%$ of funding going to landmark performing arts companies, and 20\% going to individual artists (Latham, 2004 , p. 1). The demise of small to medium arts companies has resulted in a situation where the contemporary structural organization of the arts in Australia is like a pyramid that lacks a solid foundation (Brisbane, 2006). Foreshadowing Brisbane's pyramid metaphor, Terracini (2006) has called for a rethink of the structural pyramid on which the arts in Australia is based, having at its base the work of suburban and regional arts organizations, many of which are amateur. Such organizations could be encouraged to create arts works drawn from their own communities and the sto- ries, cultures, and people found there (Terracini, 2006). This base of organizations and community engagement could create a critical mass of content and skill that would sustain the work of major arts organizations in Australian capital cities.

For change to occur on the scale proposed by Terracini (2006) and Brisbane (2006) a reconnection with and reexplanation of the arts to the community is necessary. In proposing a framework to achieve these ends, Brisbane (2006) advocates an approach grounded in creativity, innovation, and imagination, manifest as the Creative Industries paradigm (Cunningham, 2006).

\section{Tourism and the Arts}

The economic impact of tourists attending festivals has been well recognized in academic research (e.g., Chhabra, Sills, \& Cubbage, 2003; Kottke, 1988; Leitch \& Leistritz, 1985; Taylor, Fletcher, \& Clabaugh 1993). Chhabra et al. (2003) suggest that short-term events complement a region's portfolio of tourism products, including increasing demand during periods of low tourist activity and creating a positive image of a location. Chhabra et al.'s (2003) study of Scottish Highland Games festivals in North Carolina, held over a single long weekend, showed that tourists made a substantial contribution to the local economy mainly on lodging, and food and beverages (see Table 1). Sustainability is also a feature of the events with tourists expressing high levels of intention to return the following year.

Festival tourism in the form of creative industries events has achieved political and economic prominence in recent times as an important enabler of urban regeneration through the economic benefits it provides (Rogerson, 2006). Cities are also using festivals to position themselves in the marketplace (Prentice \& Andersen, 2003); for example, Edinburgh, which has sought to position itself as "the festival city" rather than just the national capital. In discussing the sectors entailed by the term "creative industries" Rogerson (2006) cites 13 sectors that include arts, design, music, and performing arts, all of which are on show at Kenilworth, the location of this study. Yet despite a focus on economic benefits, creativity and economic benefits do not exist independently, being 
Table 1

Visitors Attending Highland Games Festivals

\begin{tabular}{lccc}
\hline Event & Population (000) & Tourists (000) & $\begin{array}{c}\text { Visitors as Percentage } \\
\text { of Population }\end{array}$ \\
\hline Grandfather Mountain Highland Games & 558,000 & 17,100 & 3.05 \\
Flora MacDonald Highland Games & 113,000 & 4,100 & 3.63 \\
\hline
\end{tabular}

Source: Chhabra et al. (2003).

interwoven into the fabric of festivals (Rogerson, 2006).

In addition to their role in urban regeneration, events and festivals are also enablers of regional development, mainly through noneconomic factors (Moscardo, 2007). Factors contributing to rural development include building social capital, enhancing community capacity, and providing support for ancillary products and services. Integrating communities through increased interaction amongst residents; increased socialization; and relationship building enhances social capital. Festivals also assist in building local and regional identities, which are built through an increased sense of place (Moscardo, 2007). Community capacity is enhanced through the development of skills, including those involved in planning and running the event itself (Moscardo, 2007).

Getz (2008) discusses festivals as cultural celebrations that are planned events. He points out that a feature of festivals is that subsequent offerings are never the same as the previous offering, supporting Phelan's (1996) argument that performance "only has a life in the present" (p. 146). Getz (2008) proposes a portfolio approach that considers the strategy and implementation of events from the perspectives of organizers and participants. The model suggests that periodic local events will have low demand and low value, and will be measured mainly in economic terms. Where arts festivals are concerned Getz (2008) argues that they are events that "display a lack of concern for tourism and take a product orientation that tends to ignore customer needs and commercial realities" (p. 407).

The arts, through arts festivals, play an important role in tourism that extends beyond the usual definitions of events (e.g., a marketing approach with tourism objectives) (Quinn, 2006). Quinn
(2006) describes festivals as "socially significant cultural practices" (p. 289) that extend beyond the domains of tourism and economy. Quinn supports her argument about the value of arts festivals in a study of arts festivals in Ireland. Two long-standing festivals that had their genesis in local needs and development are considered. Both festivals have had a major impact on arts development in their locations over many years.

Governments often provide financial support for festivals, based on the notion of job creation and increased future visits (Dwyer, Mellor, Mistilis, \& Mules, 2000). However, beyond the economic imperative for funding there is a realization that festivals also provide social and cultural benefits. A key question is what degree of government support is warranted, which varies according to the perceived benefits and costs associated with the event. Events may incur a financial loss yet still provide benefits to the community, while costs include noise, traffic congestion, etc. Dwyer et al. (2000) have developed a framework for evaluating what events should be supported from public funds. Also identified are intangible benefits that include social benefits such as: community development including facilities that may be used by the community after the event; increasing community interest and involvement; increasing or providing educational opportunities; civic pride based on a sense of pride and excitement related to a community or region; and the ability of festivals to engage with youth, the elderly, underprivileged etcetera. Long-term benefits may also include heightened awareness of a destination, the possibility of return visits and the development of new market-based opportunities.

The issue of whether festivals can provide a basis for sustainable tourism has been raised by Quinn (2006) in the context of her study of major 
regional festivals in Ireland. A further issue is whether tourism can enhance the social benefits provided by festivals on an ongoing basis. Sustainability entails improving the social, community, and economic well-being of communities on a continuing basis. Therefore, a key role of festivals in relation to tourism is in enhancing the part that tourism plays in sustaining communities. Quinn (2006) argues that many festivals are not sustainable as they leave no legacy other than their name and memories held by audiences.

\section{The Creative Industries Paradigm}

Cunningham (2006) proposes an alternative view on the place, purpose, and capacity of arts, culture, and creativity in communities. The combined effects of technological advances, changing tastes, and emerging talent through different channels, present formidable challenges to traditional approaches to growing arts consumption and its support base. Traditional arguments about the value of the arts and culture have lost their currency, failing to meet the prerequisites and accountabilities that governments and their arts funding agencies are now employing (Cunningham, 2006). Instead, a more pragmatic approach is needed, one that gives particular attention to "what are usually called the ancillary benefits of culture and creativity manifest through economic opportunity and innovation, social inclusion and educational advantage" (Cunningham, 2006, p. 44).

Cunningham (2006) argues that the creative industries concept has gained significant attention in contemporary government, industry, and policy debate. Indeed, the concept has been influential on government policies in many countries (e.g., UK, Singapore, Hong Kong, Australia), and locally through the Queensland state government. Through the Creative Industries paradigm, Cunningham (2006) seeks to reshape relationships and reposition media, culture, and communication as "a driver rather than a passenger in the knowledge economy" (p. 14).

The Creative Industries paradigm is based primarily on the work of Caves (2000), Florida (2002), Leadbetter (2003), Hartley (2005), and Cunningham (2006). The paradigm views creativity as an important economic asset, arguing that nations that prosper in the $21 \mathrm{st}$ century will be those that embrace and support the creativity of their people and communities. The creative industries comprise not only the traditional cultural sectors such as the visual and performing arts, but also include film and television, web design, broadcasting, computer animation, music, architecture and urban design, writing, industrial design, designed fashion, and publishing (Cunningham, 2006). The common thread running through all of these sectors, which is also the currency of creative industries, is the knowledge gained through human creativity. Creative industries share many of the characteristics that are common to the arts industry, categorized by Caves (2000) as: a) uncertain demand; b) creative workers care about their product; c) collective production methods; d) infinite variety of products; e) variation in perceptions of quality; f) completion of diverse activities in short time frames; and g) long-term durability of many creative products.

For this study the Creative Industries paradigm has promise. As a strategy or policy framework it proposes a new language with which to explore, and perhaps to renew, understanding of how terms like "creativity," "innovation," and "the arts" may be applied in 21 st century community life. It opens up the way for the arts to engage in the corporate discourse that governs so much private and public activity in our community. The key elements of the Creative Industries paradigm are listed in Table 2. These elements have been drawn from a number of different sources as indicated in the text. The researchers have sought to synthesize the nuances of meaning. At the end of each description are guiding questions to focus application of the Creative Industries paradigm to the particular rural community and arts event that is the subject of this study.

\section{The Context of the Study}

The township on which the study is based is Kenilworth, a small community in the Queensland hinterland with a population of about 250 people. The township, like many other rural communities, is dealing with profound economic and social changes. Economic restructuring and drought have radically altered the mainly agricultural traditional 
Table 2

Key Terms of the Creative Industries Paradigm

Creative Industries Element

Description

Creativity

Clusters

Critical mass

Flow on effect

Multiple pathways

The experience economy

Job and wealth creation

Favorable conditions/ supportive environment

Knowledge/intellectual property

Social and cultural capital
Generating new ideas or new combinations of old ideas. "Creativity will be the driver of social and economic change during the next century" (Hartley, 2005, p. 1).

Q: What are the special skills in this community? How is the festival animating creativity in its community?

This concept is a key building block and is "a geographically proximate group of interconnected companies and associated institutions in a particular field, linked by commonalities and complementarities" (Porter, 2000, p. 261).

Q: What are the networks in this community? Is the festival a point of connection? What kinds of connections are being made at the festival?

May be defined as "a size, number, or amount large enough to produce a particular result" (Oxford Dictionary, 2008).

Q: Does the festival create a critical mass in the community?

“A major attribute referring to 'the flow-on' effect to other industries. Emphasizes the importance of building collaborative links with related sectors such as education, tourism, research, innovation and lifestyle. A value chain analysis of the sector can reveal a complex network of connected individuals, businesses and related industries" (Henkel, 2006, p. 11; Preece, 2005).

$\mathrm{Q}$ : What is the nature and extent of the flow on effect in the community?

Key idea, in that there are many ways to solve a problem, generate a new idea, to engage in an event.

Q: Does the festival create multiple pathways for community participation?

"Experiences are replacing goods and services because they stimulate our creative faculties and enhance our creative capacities" (Florida, 2005, p. 136).

Q: What is the unique about this community? What are the community assets? Does the festival add to the experience of this community?

For many governments this is the key attraction of the Creative Industries paradigm. For some it emerged "out of Blair's Britain in the late 90 s as an antidote to post-industrial unemployment" (Lovink \& Rossiter, 2006, p. 1).

Q: Who does the festival partner with in order to create a critical mass of opportunities? Does the festival generate jobs and income for the community?

Arises out of Florida's basic argument "that regional economic growth is powered by creative people who prefer places that are diverse, tolerant and open to new ideas" (Florida, 2002, p. 249; Putman, 2000).

Q: What makes things happen in this community? What combination of people, place, and purpose have caused energy and excitement, or emphasized a sense of connection between those who live in this town? Who or what is benefiting from the favorable conditions that the festival is creating?

Intellectual property can be generated by Creative Industries-type activities (Cunningham, 2006, p. 5).

Q: What do we know about this place? Its people, history, successes, failures, its aspirations, its potential? What do we know about this place that no one else will know? What knowledge, new ideas, skills and pathways does the festival generate?

These terms refer to the enabling quality of the connections and relationships in a community, and the capacity to participate in activities that are significant to community members. Artists, musicians, picture makers and storytellers capture and preserve local culture and history and contribute to a community's social and cultural capital (Henkel, 2006, p. 11).

Q: What groups or events are important to the way things are done around the community? Are there new groups, families or individuals moving into the area? What contribution does the festival make to the community's social and cultural capital? 
industries, with many people who lived in the area moving to the city. Nevertheless, the area is popular with tourists, painters, and photographers wanting to take advantage of the acclaimed light that can be found around the township. The township has one main street accommodating small businesses, services, two commercial galleries, and an arts and crafts store. An information center, staffed by volunteers, provides information on local activities, including arts and cultural activities. Within 15 kilometers of the town are two boutique wineries and an extensive range of properties offering accommodation.

A key element of the study was the relationship between the commercial businesses in the community and the members and activities of the local Arts Council. An intriguing initial discovery was that alongside one of the galleries an embryonic Creative Industries-type precinct was being established, containing a contemporary art gallery, jewelry making, and a massage/natural therapies store. From personal experience, the principal researcher would argue that almost every rural community in Australia, be it large or small, has an arts show. Painters and sculptors from all over the country enter works hoping to sell them and possibly win one of the cash prizes that are often available. About 9 years ago the organizers of the annual rodeo event invited the local Arts Council to provide some artwork to complement the rodeo. As time went by the arts section got bigger and bigger until the hall could no longer contain them. At this point the Arts Council decided to stage its own event on a different weekend to the rodeo.

\section{Kenilworth Celebrates!- The Brand}

The current festival is now a flourishing weekend-long event based around the arts show. The event has been branded Kenilworth Celebrates! in order to broaden its appeal and to underline the celebratory nature of the arts and this community. Kenilworth Celebrates! is a fiesta, a party for all lovers of arts and small communities, a pageant of art. Other key events are the Poets Breakfast, a Creative Arts and Crafts market, along with exhibitions of art and music performances at churches throughout the weekend. One way of assessing the success of the festival is the number of tourists visiting Kenilworth during the festival. Kenilworth has a population of 250 persons and is a 2-hour drive from Brisbane, yet it attracted over 1,000 visitors over the 3 days of the festival. The scene is described by the principal researcher reflecting on the first day of the festival:

\begin{abstract}
There is a very steady stream of people through the shops in the main street-the coffee shop is doing a roaring trade and the butcher is struggling to keep up with demand. The Lasting Impressions gallery is very busy and there are many people taking a leisurely stroll up and down the main street, in and out of all the shops, the galleries and the hall. (Mitchell, 2007, p. 24)
\end{abstract}

In recent times, strategic planning has led to the area, both indoors and outdoors, becoming an "arts space" where other spaces could be used for visual arts projects and innovative arts presentations. In 2006, the local authority contributed an award of $\$ 10,000$, establishing Kenilworth in the professional arts world as a significant event. In order to maintain amateur artists with some or no professional ambitions, the Arts Council maintained the range of small awards that it had traditionally offered. Three other key initiatives were also introduced: a) the well-established professional art gallery would display the winner and short listed entries; b) a local winery would display all entrants that did not make the short list; and c) a third gallery would display children's art work sourced from the local school. The first two initiatives provided important exhibition time for entrants in the art show to make their work available for same. Art was spreading out.

The creative reputation of Kenilworth Celebrates! has been instrumental in building and maintaining the brand (Powell, 2007). As Powell (2007) suggests, the brand has been developed through word of mouth, media publicity, and industry awards particularly the sponsorship of the local authority, and the involvement of local businesses. The future identity of Kenilworth Celebrates! will be sustained through active management of the brand. In proposing a framework for understanding brand management in creative industries, Andriopoulos and Gotsi (2000) suggest that creative organizations should regard creativity as a priority in achieving innovation, which in turn 
is vital in strengthening brands that then link back to creativity in a continuous spiral (Andriopoulos \& Gotsi, 2000). Development of the brand Kenilworth Celebrates! is augmented by the framework for growth of the festival proposed in Table 3 , which is based on the Creative Industries paradigm through its focus on creativity. The link between Kenilworth Celebrates! as a brand and the paradigm is also evident in the Experience Economy element of the paradigm, which demonstrates increased tourism by showcasing the brand to locals (branding at the community level) and visitors.

\section{Methodology}

As discussed above, three points of view framed and provided the basis for development of the project: a) the Creative Industries paradigm; b) the knowledge, experiences, and responses of people engaged in an arts event in a rural community; and c) the principal researcher's own creative practice. This three-pronged information base was informed by the principal researcher's professional experience and research approach based on consultation, partnership, and collaboration. This is the approach of the animateur and can be explained in terms of cultural animation, where animation means to stimulate, stir or to rouse (Reynolds, 1984). As Reynolds (1984) further argues "the animateur is a community artist who helps people create and celebrate their own culture, drawing freely on the particular aspirations, myths, ethnic or historical heritage that bind them as a community" (p. 33).
In order to examine the capacity of the Creative Industries paradigm to act as a stimulatory framework for arts practice in a rural community, it was necessary to understand the actions and motivations of members of that community. Once established, the task was then to evaluate this material against the concepts and language of the paradigm. The primary research material pursued was qualitative and was drawn from opinions, ideas, experiences, and attitudes gained through interviews and conversations. In addition, community representatives requested information on relevant outcomes as they arose in order to incorporate them into reflection and planning for future activities. In view of the transformational nature of the research, together with the involvement of people affected by the change, an action research approach was chosen (Lewin, 1951). Action research has the dual aims of bringing about change in a community, program, or organization while increasing the understanding of the researcher or community or both (Dick, 1993). Given the transformational and contemporaneous nature of the research, together with the limitation of the study to a particular rural community in Australia, the research is presented as a qualitative case study (Easterby-Smith, Thorpe, \& Lowe, 2002). Case studies are the preferred method when "how" and "why" questions are being posed, the researcher lacks control over the events, and the study has a contemporary focus (Yin, 2003). These characteristics also contribute to the appropriateness of a case study approach for this study as the research question being posed is a "how" question (how

Table 3

Framework for Growth of Kenilworth Celebrates!

Activity Areas

Innovations

Fresh knowledge

New friends for culture and the broader community
Increasing use of Kenilworth buildings, infrastructure, and environment as "art spaces." Diverse art forms and media introduced by the festival. Growth of arts expertise and exposure through responsibility for the Mayor's Acquisition Prize.

Management of the growth of the festival in terms of partnerships, the numbers attending, the numbers of artists exhibiting, the ideas that have arisen in terms of the festival's growth.

Between the festival and the commercial arts sector-galleries. Between the festival and the commercial sector of the community as the event continues to attract increasing numbers. Between the festival and local government in terms of the delivery of the Mayor¥s Acquisition Prize. Tourists visiting the area for the first time and valuing the experience. Potential of other government organizations to participating in Kenilworth Celebrates! 
can engagement of the Creative Industries paradigm animate the activities of a volunteer operated local arts group in a rural Queensland community?), the researcher has no control over the events being studied (i.e., behaviors of participants in the study cannot be controlled by the researcher in his role as animateur in this instance), and the study has a contemporary focus. Finally, the case study approach is advantageous and appropriate for this study as it gives the researcher the opportunity to use different sources of evidence, thus enabling triangulation of data which contributes to the accuracy of research (Yin, 2003).

\section{Data Collection and Analysis}

Data were collected by means of open ended, unstructured, in-depth conversations with key individuals at the location of research. Participants were encouraged to speak freely about their views, experiences, aspirations, and ideas. People interviewed were chosen on the basis of their extensive experience in arts in their local rural community. Participants contributed by means of anecdotes, stories, and experiences, good and bad. They also contributed in ways that required flexibility in terms of time of meeting, location and means of communication. Some people were very comfortable with face-to-face interviews, others preferred to respond by email while others favored an informal "chat" on the bench outside the newsagents on the town's main street.

Peer interviews were conducted with professional regional arts practitioners in both the private and public spheres. Also, 15 people were interviewed in the rural community, on which the case is based, with interviews recorded via voice recorder. Hand-written notes were made during and immediately after each interview to capture nonverbal communication. Interviews were transcribed and analyzed as soon as possible after each interview. Concepts were noted using the constant comparison method advocated by Strauss and Corbin $(1990,1998)$ and subsequently built into categories or themes. A list of concepts is provided in Table 4.

The local arts council hosted a festival that brought together traditional and innovative arts practice in a major visual arts exhibition, two smaller exhibitions, recitals, and a range of community-based activities. The principal researcher had in-depth knowledge of the community having worked with the local Arts Council on a previous occasion.

\section{Evaluating the Outcomes}

Kenilworth Celebrates! experienced great success in its ninth year of operation, with increases in every aspect of the festival. In order to assess the impact of the festival, the themes emerging from the data, together with demographic information, were juxtaposed with the work of Matarasso (2004), which examines the impacts of arts touring on regional communities. In his study, Matarasso (2004) reports the arts as having certain artistic, community cohesion, and development benefits. The benefits identified by Matarasso together with the thematic analysis from the research are shown in Table 5.

Table 5 provides a broad framework for discussing the impact of Kenilworth Celebrates! The comparative analysis shows that Kenilworth Celebrates! performed well against each of the six benefits of the arts to rural communities listed by Matarasso (2004). At the end of the festival the committee felt that the festival had been a resounding success. The arts show's impact on the township reflected arts capacity to "set the pace" in the community by providing new and challenging experiences that enabled new ideas to be discussed and shared.

Outcomes from the festival were also juxtaposed with the elements of the Creative Industries paradigm as shown at Table 2. The elements of the Creative Industries paradigm are compared with the corresponding outcomes provided by the Kenilworth Celebrates! committee, and are shown at Table 6 , below.

The table shows how strongly the arts show was represented in each element. Initially, what is challenging in employing the Creative Industries paradigm in exploring the capacities of Kenilworth Celebrates! are the differences of size and scale. The paradigm is often employed on a larger scale than is available in Kenilworth. Hartley (2005) argues that initiatives in the Creative Industries area require a mix of public and private business, using 
Table 4

Concepts Emerging From the Data

Theme

Concepts

Access to the arts

Increase in tourists, increased exhibits, qualified judges, attraction for tourists, increased exhibits, strong visitor numbers, steady stream of people

Diversity and choice Diversity of arts experiences, expanded exhibitions, satisfaction from the work

Experience

Festival atmosphere, people gathering, milling around, lots of excitement, community experience of art

Integrating

Community building

Shared experiences, business partnerships, connections between people

Building viable future Making links, local skills, increased use of community facilities, quality of life, bigger and better communities

Arts show, community meeting place, promotion of local creativity, community relationships, engaging people, major prize, economic benefit, volunteer working community

next year, flow-on effect, clustering effect, energy site for community activities

success stories from Silicon Valley and collaboration between Creative Industries in London and the university and government sectors. In Australia, creative industries development seems more often to be conceived as occurring in areas of large population numbers and in a more urban context than Kenilworth.
Despite limitations related to size, it is possible to identify key connections between Kenilworth Celebrates! and the Creative Industries paradigm. The festival generates substantial economic activity through extra income for the town's businesses, substantial sales of art works, while providing opportunities for emerging artists. The

Table 5

Community Benefits Table: Kenilworth Celebrates!

Benefits of Arts in Rural Description of Key Benefits Communities $\quad$ From Matarosso (2004)

Access to the arts

Diversity and choice

A unique experience

Bring people together

Community development

Viable communities overcomes social isolation.

Skills gained in managing and facilitating arts events brings as community benefits. Local experience.

Access to high-quality arts work, enabling and engaging with local community.

Extends range and type of arts locally. Increases local engagement and participation. Confirms or challenges community taste.

Brings art into their own environment where they are comfortable. Art is accessible.

Role in changing social and economic environment. Contribution to community development and maintenance, social capital and voluntary activity.
Kenilworth Celebrates! 2006 Processes and Outcomes

High profile competition judges attend and praise the quality of work in the arts show, increased entries, expanded place.

Wide range of art in terms of quality, content, and media used. Diverse exhibition locations used including church.

Kenilworth hall becomes art gallery with diverse range of art. Provides intimate experience of art for community.

People attending comprise visitors, new arrivals and residents.

Over 1,000 tourists viewed the exhibition; an increase of $40 \%$ from previous year. 9th year of running successful art show.

Local businesses offering lodgings, food and beverages all experienced strong visitor numbers. Main street commercial businesses reported year's best weekend trading. 
Table 6

Creative Industries Elements Evident in Kenilworth Celebrates!

Creative Industries Element

Kenilworth Celebrates! Demonstrates Creative Industries Through:

Creativity: How is the festival ani- Promotion of the creative and innovative capacities of community organizations and mating creativity in its community?

members, or artists and artistic skills residing in community.

Clustering: Is the festival creating clusters in the community?

Creates a temporary cluster site in that a large number of people ( 1,000 over 3 days) gathered to create a critical mass of interest in the festival. This temporary critical mass creates positive impact on town, business, community, and new and connected projects stimulated by the arts show.

Flow on effect: Does the festival create a flow on effect into the community?

Instigates positive flow from the festival to the town galleries, other creative industries in the area and commercial businesses who benefit in patronage terms from people attending the festival.

Multiple pathways: Does the festival create multiple pathways for community participation?

New ways to engage people as in arts activities - new venues, art media (digital), art making opportunities, forging links with arts communities, animateurs, practitioners, and audiences elsewhere.

The experience economy: What is the unique Kenilworth experience?

The Kenilworth Celebrates! brand makes the district more attractive for tourists and residents: arts interactions at many levels, wineries, restaurants, B\&Bs, historical sites. Showcases the brand to locals and visitors.

Job and wealth creation: Does the festival generate jobs and income for the community?

Favorable conditions/supportive environment: Is the festival creating favorable conditions for the building of partnerships?

Generates income through the selling of art and for many businesses from the large increase of people visiting the arts show. 1,000 people visited the area over the weekend of the festival.

Development of community connections and relationships via building partnerships with business commercial arts and other community organizations. These connect to tourism, education and the local business sector. Shared community experiences and new directions for community development.

Knowledge/intellectual property: What knowledge/intellectual property does the festival generate?

Grows awareness of community, social and economic issues and relationships, developing entrepreneurial instincts and skills, forming links with other sources of knowledge, skills etc. Develops new ways to engage as many people as possible in arts activities.

Cultural and social capital: What contribution does the festival make to Kenilworth's social and cultural capital?

Creates important meeting place for community, places that are becoming critical as communities change and traditional events are discontinued. Increases opportunities for local community to attend and participate in significant social and cultural events.

local authority prize of $\$ 10,000$ raised awareness of Kenilworth and attracted more art. Key elements of the Creative Industries paradigm that have relevance for Kenilworth include: a) clustering/critical mass; b) building partnerships and the flow on effect from this; c) multiple pathways for cultural and economic engagement; and d) generation of artistic and social capital. While these may not be as significant in an absolute sense as in more typical Creative Industries sites, they are significant in the context of the festival and the Kenilworth community. As Table 6 shows, Kenilworth Celebrates! performs effectively in a range of key areas pertinent to Creative Industries (e.g., promoting creative and innovative capacities in the community). The next question is how can the analysis provided by the Creative Industries para- digm assist Kenilworth Arts Council to build on the success of the festival in future years?

Applying the Creative Industries paradigm to the outcomes of the festival strongly emphasizes the benefits that Kenilworth Celebrates! brings to the community. The festival brings people together, provides access to a diverse and high quality experience of the arts, and contributes to community viability through community development. These benefits connect directly with the key ancillary benefits identified by Cunningham (2006) who describes them as "economic opportunity and innovation, social inclusion and educational advantage" (p. 44). Cunningham (2006) argues that if a case is to be made for the legitimacy of the arts in our community that it must be made by emphasizing these benefits and a "defence of the 
innovations, the fresh knowledge and the new friends for culture" (p. 44).

So what are the innovations, the fresh knowledge, and the new friends for culture and the broader community that arise from Kenilworth Celebrates!? Table 3 takes Cunningham's question and explores how the festival makes a case for the proper place of arts in the community, highlighting the base from which the festival can grow.

Making a case for the arts in the community involves not only a much broader appreciation of the capacities of creativity, and of the arts, but also how communities, their resident community organizations, corporate, and government structures can respond and engage with each other.

\section{Discussion and Conclusion}

Kenilworth Celebrates! is a successful arts festival that attracts high numbers of tourist, particularly when assessed on a per capita basis. As Chharba et al. (2003) argued in their study of Highland Games events in North Carolina, tourist numbers of between $3 \%$ and $4 \%$ of the populations are regarded as attendances that underpin successful and sustainable events. Given that Kenilworth is a small rural community that generates tourist number four times the local population the impact of tourism is substantial.

The success of Kenilworth Celebrates! does not support the findings of Getz (2008) that arts festivals show a lack of regard for tourism and ignore customer needs. The operation of the Creative Industries paradigm (see Table 6), together with the reflection of the principal researcher clearly show an appreciation of the value of tourism and customers of the festival.

On the issue of sustainability (Quinn, 2006) the researchers would argue that Kenilworth Celebrates! as seen through the lens of the Creative Industries paradigm does provide a basis for sustainable tourism. The framework for growth of Kenilworth Celebrates! (see Table 3) argues an increasing use of infrastructure as art spaces, suggesting that the festival leaves a legacy that is more than just memories in the minds of tourists and residents.

The Creative Industries paradigm has been applied as a comparative framework to explore the potential of present and future activities of a volunteer arts group in a small rural Queensland community. The paradigm is a tool that provides the ability to look again at what a group is doing and can do in the future. The paradigm renews understandings of what creativity is and the role it can play in the community. Renewal is achieved through refurbishing and reconsidering what the capacities of creativity and the arts can be in the broader community. The paradigm provides an opportunity to make a cohesive and meaningful argument that acknowledges the importance of individual and group creativity and shows how the arts and cultural industries can participate and contribute to it. Kenilworth Celebrates! is a festival that is testimony to the effectiveness of the paradigm in developing the brand based on creativity and innovation.

Creativity is found not only in the arts but also in many areas of the community, where many people bring creativity to their work, their activities, and their interests. The Creative Industries discourse acknowledges the inventiveness or creativity that can be found in many people's lives. As Dissanayake (1995) has argued, art is "a way of making special" (p. ix). By making special we show a care, a concern or ascribe a value to things that are important to us, that impress us. We then elevate, highlight, and celebrate them through painting them, making music about them, writing about them, and telling stories about them. The Creative Industries paradigm provides a broader range of perspectives on what creativity is and how it can be acknowledged and embraced.

The activities of a volunteer operated local arts group in a small rural community can be stimulated by engagement with the Creative Industries paradigm. However, to do this successfully, the community's already significant experience, skills, and achievements must drive and shape the sorts of responses the community has to the framework of the Creative Industries paradigm. The success of Kenilworth Celebrates! demonstrates the level of experience and knowledge that exists in the community. The key idea is not to impose policy or structure from outside, but to have the Creative Industries paradigm guide and respond to the best of what is available in the community. As demonstrated in this research, the way forward is to adapt the Creative Industries paradigm to suit the condi- 
tions in the community, not the other way around; a reversal of the usual approach to the delivery of government policy and resources.

The authors foresee future use of the Creative Industries paradigm as a framework for analyzing complex and confronting issues such as socially creative business and social capital. The relationship between these ideas and their application for the broader community continues to be difficult for many to understand and adopt. It seems that the key is how the connection is made between what theory says and the nature of the real experience. The Creative Industries paradigm provides an approach that can assist in this regard.

\section{References}

Andriopoulos, C., \& Gotsi, M. (2000). Benchmarking brand management in the creative industry. Benchmarking, 7(5), 360-372.

Brisbane, K. (2006). Imagining a creative nation. Elizabeth Jolly Lecture. Retrieved from http://www.currencyhouse. org.au/pages/downloads.html

Carey, J. (2005). What good are the arts. London: Faber and Faber.

Caves, R. (2000). Creative industries: Contracts between art and commerce. Cambridge, MA: Harvard University Press.

Chhabra, D., Sills, E., \& Cubbage, F. (2003). The significance of festivals to rural economies: Estimating the economic impacts of Scottish highland games in North Carolina. Journal of Travel Research, 41, 421-427.

Cunningham, S. (2006). What price a creative economy. Adelaide: Hyde Park Press.

Dick, B. (1993). You want to do an action research thesis: Thesis resource paper. Retrieved from http://www. scu.edu.au/schools/gem/ar/art/arthesis.html

Dissanyake, E. (1995). Homo aestheticus. Seattle, WA: University of Washington Press.

Dwyer, L., Mellor, R., Mistilis, N., \& Mules, T. (2000). A framework for assessing "tangible" and "intangible" impacts of events and conventions. Event Management, 6, 175-189.

Easterby-Smith, M., Thorpe, R., \& Lowe, A. (2002). Management research: An introduction. London: Sage.

Florida, R. (2002). The rise of the creative class and how it's transforming work, leisure, community and everyday life. New York: Basic Books.

Florida, R. (2005). The experiential life. In J. Hartley (Ed.), Creative Industries. Carlton, Australia: Blackwell Publishing.

Getz, D. (2008). Event tourism: Definition, evolution and research. Tourism Management, 29, 403-428.

Gibson, L. (2001). The uses of art: Constructing A ustralian identities. St Lucia, Queensland: University of Queensland Press.
Hartley, J. (2005). Creative industries. Carlton, Australia: Blackwell Publishing.

Hawkes, J. (2001). The fourth pillar of sustainability. Melbourne: Common Ground Publishing.

Henkel, C. (2006). Imagining the future 2. Screen and creative industries in the Northern Rivers Region of NSW: Development trends and prospects for the next decade. Sydney, Australia: Northern Rivers Regional Development Board and the NSW Department of State and Regional Development.

Kingma, O. (2004). Reconstructing communities: Policies for a different society. Delivered at the Fourth Pillar of Sustainability Conference, Melbourne, November 29-30.

Kottke, M. (1988). Estimating economic impacts of tourism. Annals of Tourism Research, 15(1), 122-33.

Latham, C. (2004). Survival of the fittest. Platform Papers, $2,4-5$

Leadbetter, C. (2003). Amateurs: A twenty first century remake. In J. Hartley (Ed.), Creative industries. Carlton Australia: Blackwell Publishing.

Leitch, J., \& Leistritz. (1985). Techniques for assessing the secondary impact of recreation and tourism. In D. Propst (Ed.), Assessing the economic impact of leisure and tourism. Ashville: United States Department of Agriculture Forest Service.

Lewin, K. (1951). Field theory in social science. New York: Harper and Row.

Lovink, G., \& Rossiter, N. (2006). My creativity: Convention on international creative industries research. Institute of Network Cultures, HVA Interactive Media and Centre for Media Research, University of Ulster.

Matarasso, F. (2004). Only connect. Nottingham: Pyramid Press.

Mills, D., \& Brown, P. (2004). Art and wellbeing. Sydney: Australia Council for the Arts.

Mitchell, P. (2007). From passenger to driver: A case study that brings together a small rural Queensland town, an entrepreneurial local arts council and the Creative Industries. Unpublished master's thesis, Griffith University, Gold Coast, Australia.

Moscardo, G. (2007). Analyzing the role of festivals and events in regional development. Event Management, 11, 23-32.

Oxford Dictionary. (2008). Oxford dictionary of English. Oxford: Oxford University Press.

Phelan, P. (1996). The politics of performance. New York: Routledge.

Porter, M. (2000). Local clusters in a global economy. In J. Hartley (Ed.), Creative Industries (pp. xx). Carlton, Australia: Blackwell Publishing.

Powell, S. (2007). Organisational marketing, identity and the creative brand. Journal of Brand Management, 15(1), 41-57.

Preece, S. (2005). The performing arts value chain. International Journal of Arts Management, 8(1), 21-32.

Prentice, R., \& Andersen, V. (2003). Festival as creative destination. Annals of Tourism Research, 30(1), 7-30.

Putman, R. (2000). Bowling alone: The collapse and revival of American community. New York: Simon and Schuster. 
Queensland Government. (2004). Creativity is big business. Queensland, Australia: Queensland Government Publishing Service.

Quinn, B. (2006). Problematising 'festival tourism': Arts festivals and sustainable development in Ireland. Journal of Sustainable Tourism, 14(3), 288-306.

Reynolds, P. (1984). Cultural animation: 'Just plain folks' building culture rather than just consuming it. In Context, 5, 32.

Richards, M. (2006). Grow the arts reap the harvest. Teneriffe, Australia: Post Pressed.

Rogerson, C. (2006). Creative industries and urban tourism: South African perspectives. Urban Forum, 17(2), 149166.

Strauss, A., \& Corbin, J. (1990). Basics of qualitative research: Grounded theory procedures and techniques. Newbury Park: Sage.

Strauss, A., \& Corbin,J. (1998). Basics of qualitative re- search: Techniques and procedures for developing grounded theory (2nd ed.). Thousand Oaks, CA: Sage.

Taylor, D., Fletcher, R., \& Clabaugh, T. (1992). A comparison of characteristics, regional expenditures and economics: Impact of visitors to historical sites with other recreational visitors. Journal of Travel Research, 32(1), 30-35.

Terracini, L. (2006). The culture of place: Making Australian theatre. Australasian Drama Studies, 48, 18-29.

Yencken, D. (2001). Forward. In J. Hawkes (Ed.), The fourth pillar of sustainability. Melbourne: Common Ground Publishing.

Yin, R. (2003). Case study research: Design and methods. Thousand Oaks, CA: Sage.

Yuen, C. (2003). The water project case study: Northern Lakes Center for the Arts. Retrieved from http://www. artsusa.org/animatingdemocracy/pdf/labs/water_issues _project_case_study.pdf 